Supporting Information for

\title{
Synthesis of Platinum Nanowire Networks Using a
}

\section{Soft Template}

Yujiang Song, ${ }^{1 *}$ Robert M. Garcia, ${ }^{1,2}$ Rachel M. Dorin, ${ }^{1,2}$ Haorong Wang, ${ }^{1,2}$ Yan Qiu, ${ }^{1,2}$ Eric N. Coker, ${ }^{1}$ William A. Steen, ${ }^{1}$ James E. Miller, ${ }^{1}$ and John A. Shelnutt ${ }^{1,3^{*}}$

${ }^{1}$ Advanced Materials Laboratory, Sandia National Laboratories, Albuquerque, New Mexico 87106; ${ }^{2}$ Department of Chemical \& Nuclear Engineering, University of New Mexico, Albuquerque, New Mexico 87131; ${ }^{3}$ Department of Chemistry, University of Georgia, Athens, Georgia

AUTHOR EMAIL ADDRESS: ysong@sandia.gov; jasheln@unm.edu 


\section{Experimental Details:}

Chemicals: Potassium tetrachloroplatinate(II) (Sigma-Aldrich, $\mathrm{K}_{2} \mathrm{PtCl}_{4}, \quad 99.99 \%$ ), cetyltrimethylammonium bromide (Sigma-Aldrich, CTAB, 95\%), chloroform (Burdick \& Jackson, HPLC grade), and sodium borohydride (EMD Chemicals, 98+\%) were used as received. Large scale synthesis of the platinum nanowire networks. The synthesis of the nanowire networks was carried out on a large scale in order to generate sufficient quantities of material to allow surface area measurements. The experimental procedure used was the same as that used in the small-scale reaction except that the quantities of reagents were increased accordingly $(75 \mathrm{~mL}$ of $40 \mathrm{mM} \mathrm{CTAB}$ in chloroform, $75 \mathrm{~mL}$ of aged platinum complexes, $600 \mathrm{~mL}$ of Nanopure water, and $75 \mathrm{~mL}$ of $300 \mathrm{mM} \mathrm{NaBH}_{4}$ in water). After reaction, the mixture was distilled to remove the chloroform and then evaporated to remove water over a period of several days in an oven at $65^{\circ}$ C. $200-\mathrm{mL}$ of fresh Nanopure water added to the dried materials and the materials were resuspended by simultaneous mild sonication and stirring for 15 minutes. The black slurries were transferred to four tubes and centrifuged at 3500 RPM for at least 30 minutes to precipitate out the products. The supernatant was then removed. The centrifugation/re-suspension procedure was repeated five times to remove as much surfactant, salts and other impurities as possible. After water cleaning, the products were dried at $65^{\circ} \mathrm{C}$ for 12 hours and the above purification process was repeated five times by using $5 \times 20 \mathrm{~mL}$ of chloroform. After removal of the supernatant, the resulting black slurry was then dried in an oven for another 12 hours at $65^{\circ} \mathrm{C}$ prior to being used in the surface-area measurements.

UV-visible Absorption Spectroscopy. UV-visible spectra were obtained using a HP 8452A diode array spectrophotometer (Colorado Springs, $\mathrm{CO}$ ) and a 1-cm path length quartz cell.

Electron Microscopy and X-ray Diffraction Studies. Transmission electron microscopy (TEM, $200 \mathrm{keV}$ JEOL 2010), high-resolution TEM (HRTEM), and scanning electron microscopy (SEM, 1 30 keV S-5200) were performed on the Pt nanostructures. The samples for TEM analysis were prepared by adding drops of the colloidal suspensions onto a standard holeycarbon-coated copper grid and wicking away the excess liquid with a tissue paper. The grids were then washed several times with a mixture of Nanopure water and ethanol (1:1 volume ratio) to remove salts and surfactant molecules and air dried for at least two hours before imaging. The samples for SEM characterization were prepared using the same procedure with doped silicon wafers instead of holey-carbon copper grids. X-ray diffraction (XRD) spectra were recorded on a Siemens D500 diffractometer using Ni-filtered CuK $\alpha$ radiation with $\lambda=1.5418 \AA$ in $\theta-2 \theta$ scan mode using a step size of $0.05^{\circ}$ and a 90 -s step time. The sample was supported on a sheet of quartz.

Surface Area Measurements. The surface area of the dendritic nanostructures was measured by $\mathrm{N}_{2}$ adsorption experiments conducted on a Quantachrome Autosorb-6 instrument (Boynton Beach, FL). The cleaned and dried samples were degassed at $25{ }^{\circ} \mathrm{C}$ for at least 12 hours at 0.01 Torr before measurement. The surface area was calculated from the Brunauer-Emmet-Teller (BET) equation using a nitrogen molecular area of $0.162 \mathrm{~nm}^{2}$ and the linear region between 0.05 to 0.3 relative pressures, which gives a least square coefficient $\mathrm{R}^{2}>0.999$ for 7 adsorption points. The reported surface area and standard deviation come from 5 repetitions of the mearsurments.

Electrochemical Experiments. Electrochemical experiments were performed using the thin film voltammetric techniques developed by Schmidt et al. ${ }^{1}$ Electrodes were prepared by first making aqueous slurries of the nanostructured Pt powders with Pt concentrations from 0.2 to 1.2 
$\mathrm{g} / \mathrm{L}$. Multiple slurries were prepared to estimate uncertainties in the sample preparation procedures and the experimental measurements. Glassy carbon electrodes (GCE) $3 \mathrm{~mm}$ in diameter $\left(\right.$ area $=0.0707 \mathrm{~cm}^{2}$ ) were polished with $0.05 \mu \mathrm{m}$ Bio-Analytical Systems (BAS) alumina paste and sonicated in methanol prior to deposition of the catalyst powders. The aqueous slurries were sonicated for a minimum of 15 minutes; $5 \mu \mathrm{L}$ of the sonicated slurry was then deposited onto the cleaned GCE. The catalyst was allowed to dry before a thin-layer coating $(\sim 0.5 \mu \mathrm{m})$ of Nafion ${ }^{\circledR}$ was applied (Aldrich Nafion ${ }^{\circledR} 1100,5 \mathrm{wt} \%$ in methanol further diluted 1:10 in methanol). The resulting catalyst loadings were between 1 and $6 \mu \mathrm{g}$ of Pt, or between 14 and $85 \mu \mathrm{g}$ of Pt per $\mathrm{cm}^{2}$.

A standard three electrode cell was employed with a saturated calomel electrode (SCE) as the reference electrode, a Pt wire as the counter electrode, and the platinum catalyst-coated GCE as the working electrode (WE). All potentials are referenced to a reversible hydrogen electrode (RHE). A BAS 100B potentiostat and a 628-10 Metrohm rotating disk assembly were used for the CO-stripping experiments. CO-stripping experiments were performed at laboratory temperature $\left(20-22^{\circ} \mathrm{C}\right)$. Prior to all voltammetric experiments, each catalyst was electrochemically conditioned in a $0.5 \mathrm{M} \mathrm{H}_{2} \mathrm{SO}_{4}$ solution (Fisher Scientific $36 \mathrm{~N}$ reagent A.C.S. grade $\mathrm{H}_{2} \mathrm{SO}_{4}$ diluted with de-ionized water) by briefly $(5-10 \mathrm{sec})$ polarizing the WE to potentials where hydrogen evolution occurs (i.e., less than $0 \mathrm{mV}_{\mathrm{RHE}}$ ).

In the CO-stripping measurements, the evolved $\mathrm{H}_{2}$ was removed from the WE by rotating the electrode and then $\mathrm{CO}$ was adsorbed onto the electrocatalyst surface by holding the potential at $100 \mathrm{mV}_{\mathrm{RHE}}$ for 3 minutes in a $0.5 \mathrm{M} \mathrm{H}_{2} \mathrm{SO}_{4}$ solution saturated with ultra high purity (UHP) CO. This was done while rotating the WE at $1000 \mathrm{rpm}$ to increase mass transfer. (Preliminary experiments with longer $\mathrm{CO}$ deposition times did not result in more $\mathrm{CO}$ being deposited, so the conclusion was drawn that 3 minutes at $1000 \mathrm{rpm}$ saturates the Pt.) The potential was then swept at $20 \mathrm{mV} / \mathrm{s}$ from 100 to $1265 \mathrm{mV}_{\mathrm{RHE}}$. 9 separate electrodes for the catalyst were tested, resulting in 9 separate measurements to determine average values and standard deviations. Representative CO-stripping voltammograms are shown in Figure 6, and the procedures used in the calculation of the electroactive surface areas are described in the following.

A representative CO-stripping voltammogram for the materials tested is shown in Figure 6. The peak at about $1000 \mathrm{mV}_{\mathrm{RHE}}$ is attributed to current being passed as $\mathrm{CO}$ adsorbed on the electroactive Pt surface (Pt-CO) is stripped away from the surface (oxidized) according to the following reaction:

$$
\mathrm{Pt}-\mathrm{CO}+\mathrm{H}_{2} \mathrm{O} \rightarrow \mathrm{CO}_{2}+2 \mathrm{H}^{+}+2 \mathrm{e}^{-}
$$

The exact shape and position of the peak changes but is not significant in this study, as the parameter of interest is the charge $(\mathrm{Q})$ resulting from the $\mathrm{CO}$ oxidation event. This is calculated by integrating the background subtracted current as a function of time. Q is plotted versus $\mathrm{Pt}$ loading for the Pt nanowire networks. If the data are fit with a linear regression with a zero intercept, the electroactive surface area $\left(\mathrm{SA}_{\mathrm{e}-\text { active }}\right)$ can be calculated as follows:

$$
\mathrm{SA}_{\mathrm{e} \text {-active }}=1,000 \cdot \text { Slope } \cdot \mathrm{N}_{\mathrm{A}} / \mathrm{F} \cdot \mathrm{XSA} A_{\mathrm{Pt}} / \mathrm{n} \text {, }
$$

where the Slope is in units of $\mathrm{mC} / \mu_{\mathrm{Pt}}, \mathrm{N}_{\mathrm{A}}=$ Avogadro's number $\left(6.022 \times 10^{23}\right.$ atoms $\left./ \mathrm{mol}\right), \mathrm{F}=$ Faraday's constant $\left(96,486 \mathrm{C} / \mathrm{mol} \mathrm{e}^{-}\right), \mathrm{XSA}_{\mathrm{Pt}}=$ atomic cross-sectional area of a Pt atom $\left(8.00 \times 10^{-}\right.$

${ }^{20} \mathrm{~m}^{2} /$ atom), $\mathrm{n}=$ number of electrons in the $\mathrm{CO}$ oxidation reaction $\left(2 \mathrm{e}^{-}\right)$, and 1,000 is a metric conversion factor. The value for $\mathrm{SA}_{\mathrm{e} \text {-active }}$ is reported in the text of the paper.

(1) Schmidt, T. J.; Gasteiger, H. A.; Stab, G. D.; Urban, P. M.; Kolb, D. M.; Behm, R. J. J. Electrochem. Soc. 1998, 145, 2354-2358. 


\section{Table of Figures:}

Figure S1. Plot of frequency versus cross-section diameter for 100 randomly selected sections of platinum nanowire networks. Average size and standard deviation are given in the plot, along with the percentage ratio of the standard deviation to the average size. Reaction conditions: 20$\mathrm{mM} \mathrm{Pt}(\mathrm{II})$ and $40-\mathrm{mM} \mathrm{CTAB}$ in $10 \mathrm{~mL}$ of chloroform; $30 \mathrm{mM} \mathrm{NaBH}$ in $100 \mathrm{~mL}$ of water; stirring at $1000 \mathrm{rpm}$.

Figure S2. Plot of frequency versus cross-section diameter for 100 randomly selected sections of platinum nanowire networks. Average size and standard deviation are given in the plot, along with the percentage ratio of the standard deviation to the average size. Reaction conditions: 1 $\mathrm{mM}$ Pt (II) and $40 \mathrm{mM} \mathrm{CTAB}$ in $10 \mathrm{~mL}$ of chloroform; $30 \mathrm{mM} \mathrm{NaBH}_{4}$ in $100 \mathrm{~mL}$ of water; stirring at $1000 \mathrm{rpm}$.

Figure S3. TEM and SEM images of palladium nanowire networks. Reaction conditions: 20$\mathrm{mM} \mathrm{Pd(II)} \mathrm{in} \mathrm{40-mM} \mathrm{CTAB} \mathrm{in} 10 \mathrm{~mL}$ of chloroform; 30-mM NaBH 4 in $100 \mathrm{~mL}$ of water; stirring at $1000 \mathrm{rpm}$.

Figure S4. TEM images of platinum nanostructures at (a) low and (b) high magnification. Reaction conditions: $1-\mathrm{mM} \mathrm{Pt}(\mathrm{II})$ in $2-\mathrm{mM} \mathrm{CTAB}$ in $10 \mathrm{~mL}$ of chloroform; $30-\mathrm{mM} \mathrm{NaBH}_{4}$ in $100 \mathrm{~mL}$ of water; stirring at $1000 \mathrm{rpm}$.

Figure S5. TEM images of aggregated platinum nanoparticles at (a) low and (b) high magnification. Reaction conditions: $10 \mathrm{~mL}$ of chloroform; 2-mM $\mathrm{Pt}(\mathrm{II})$ and $30-\mathrm{mM} \mathrm{NaBH} 4$ in $100 \mathrm{~mL}$ of water; stirring at $1000 \mathrm{rpm}$. 


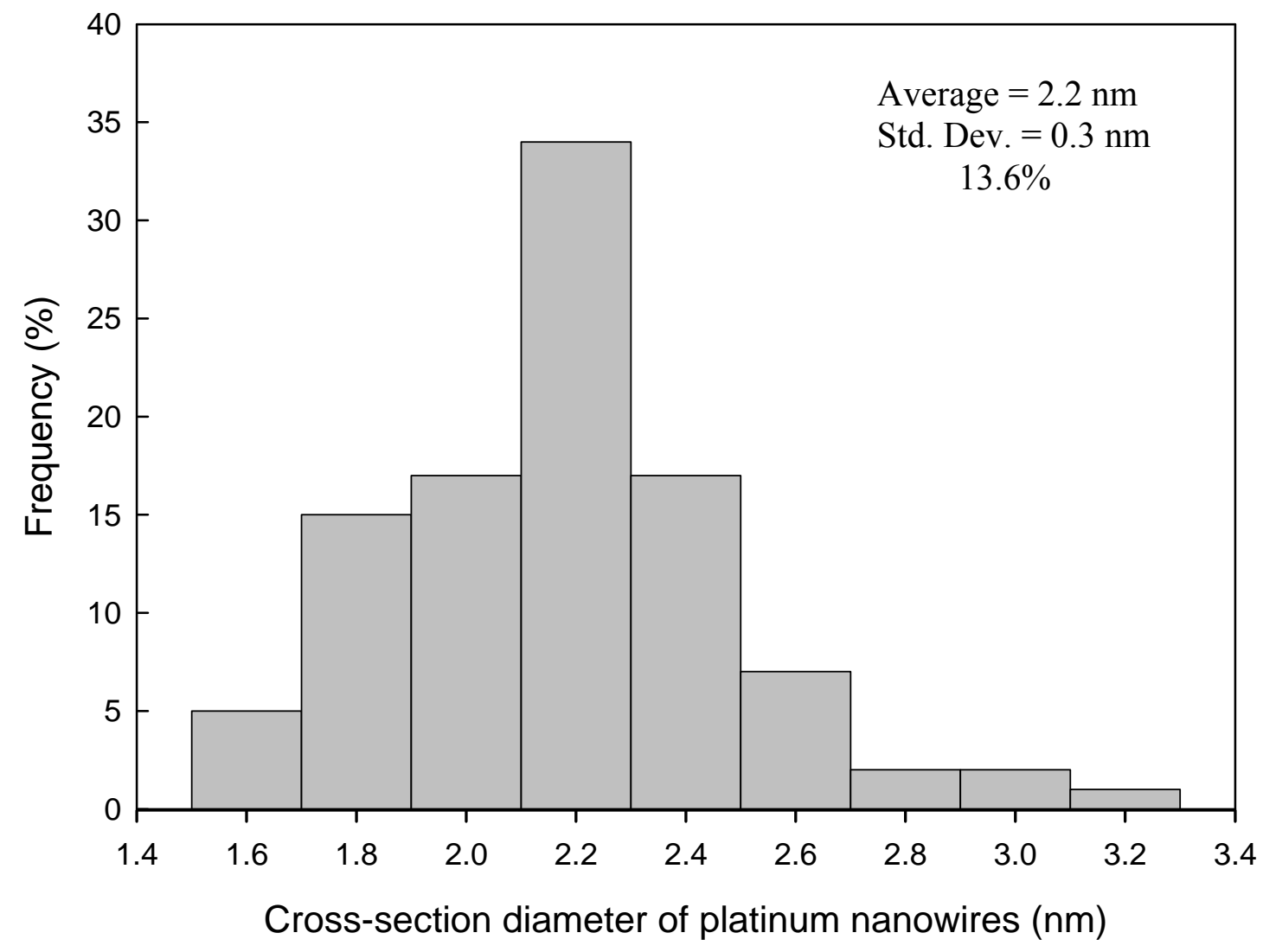

Figure S1. Plot of frequency versus cross-sectional diameter for 100 randomly selected sections of the platinum nanowire networks. Average size and standard deviation are given in the plot, along with the percentage ratio of the standard deviation to the average size. Reaction conditions: $20 \mathrm{mM}$ Pt(II) an $40 \mathrm{mM} \mathrm{CTAB}$ in $10 \mathrm{~mL}$ of chloroform; $30 \mathrm{mM} \mathrm{NaBH}_{4}$ in $100 \mathrm{~mL}$ of water; stirring at $1000 \mathrm{rpm}$. 


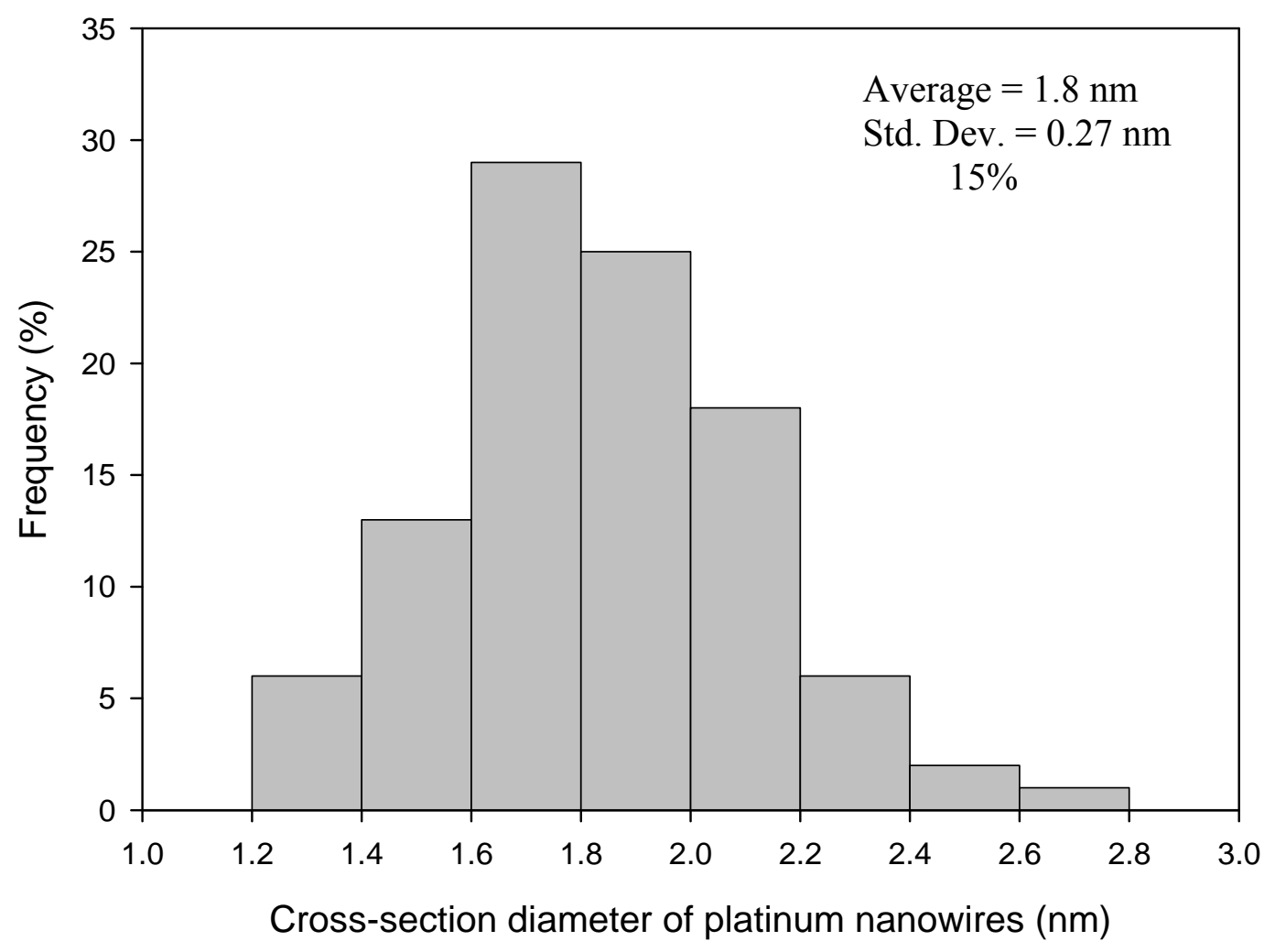

Figure S2. Plot of frequency versus cross-section diameter for 100 randomly selected sections of platinum nanowire networks. Average size and standard deviation are given in the plot, along with the percentage ratio of the standard deviation to the average size. Reaction conditions: 1$\mathrm{mM} \mathrm{Pt}(\mathrm{II})$ and $40-\mathrm{mM}$ CTAB in $10 \mathrm{~mL}$ of chloroform; $30 \mathrm{mM} \mathrm{NaBH} 4$ in $100 \mathrm{~mL}$ of water; stirring at $1000 \mathrm{rpm}$. 


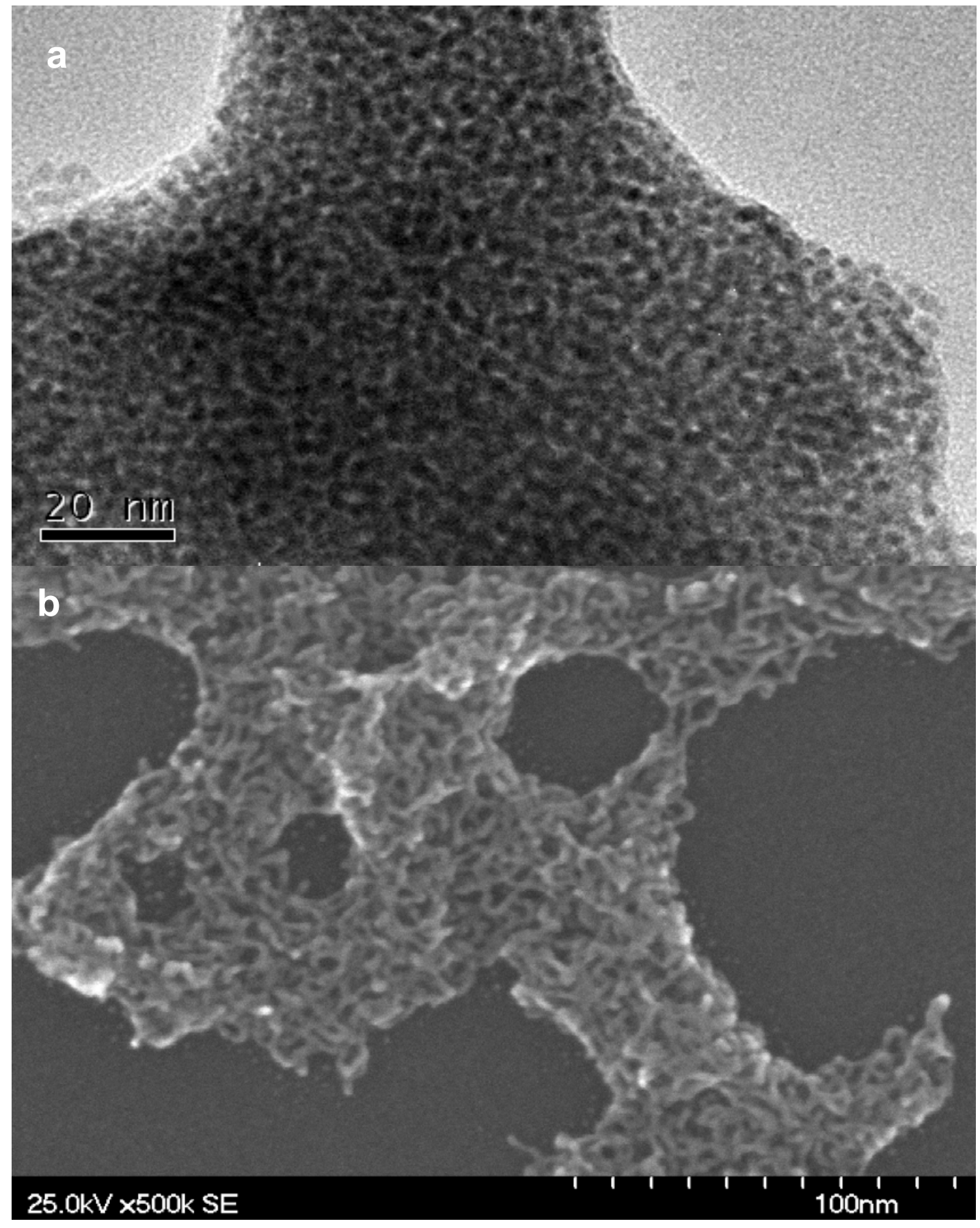

Figure S3. TEM (top) and SEM (bottom) images of palladium nanowire networks. The network structure is more evident in the SEM image. Reaction conditions: $20-\mathrm{mM} \operatorname{Pd}(\mathrm{II})$ in $40-\mathrm{mM}$ CTAB in $10 \mathrm{~mL}$ of chloroform; $30-\mathrm{mM} \mathrm{NaBH}_{4}$ in $100 \mathrm{~mL}$ of water; stirring at $1000 \mathrm{rpm}$. 


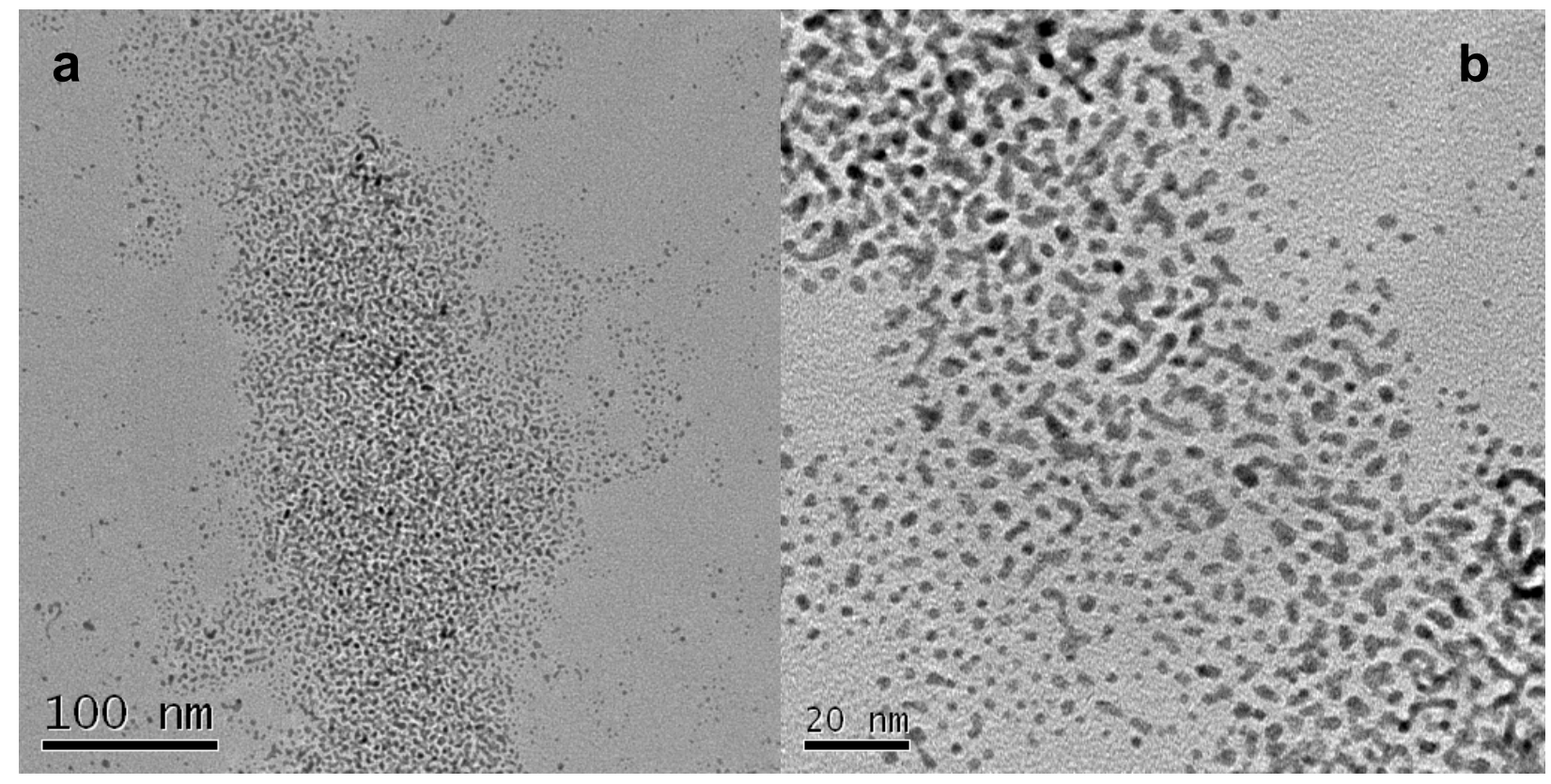

Figure S4. TEM images of platinum nanostructures at (a) low and (b) high magnification. Reaction conditions: $1-\mathrm{mM} \mathrm{Pt}(\mathrm{II})$ in $2-\mathrm{mM} \mathrm{CTAB}$ in $10 \mathrm{~mL}$ of chloroform; $30-\mathrm{mM} \mathrm{NaBH} 4$ in $100 \mathrm{~mL}$ of water; stirring at $1000 \mathrm{rpm}$. 


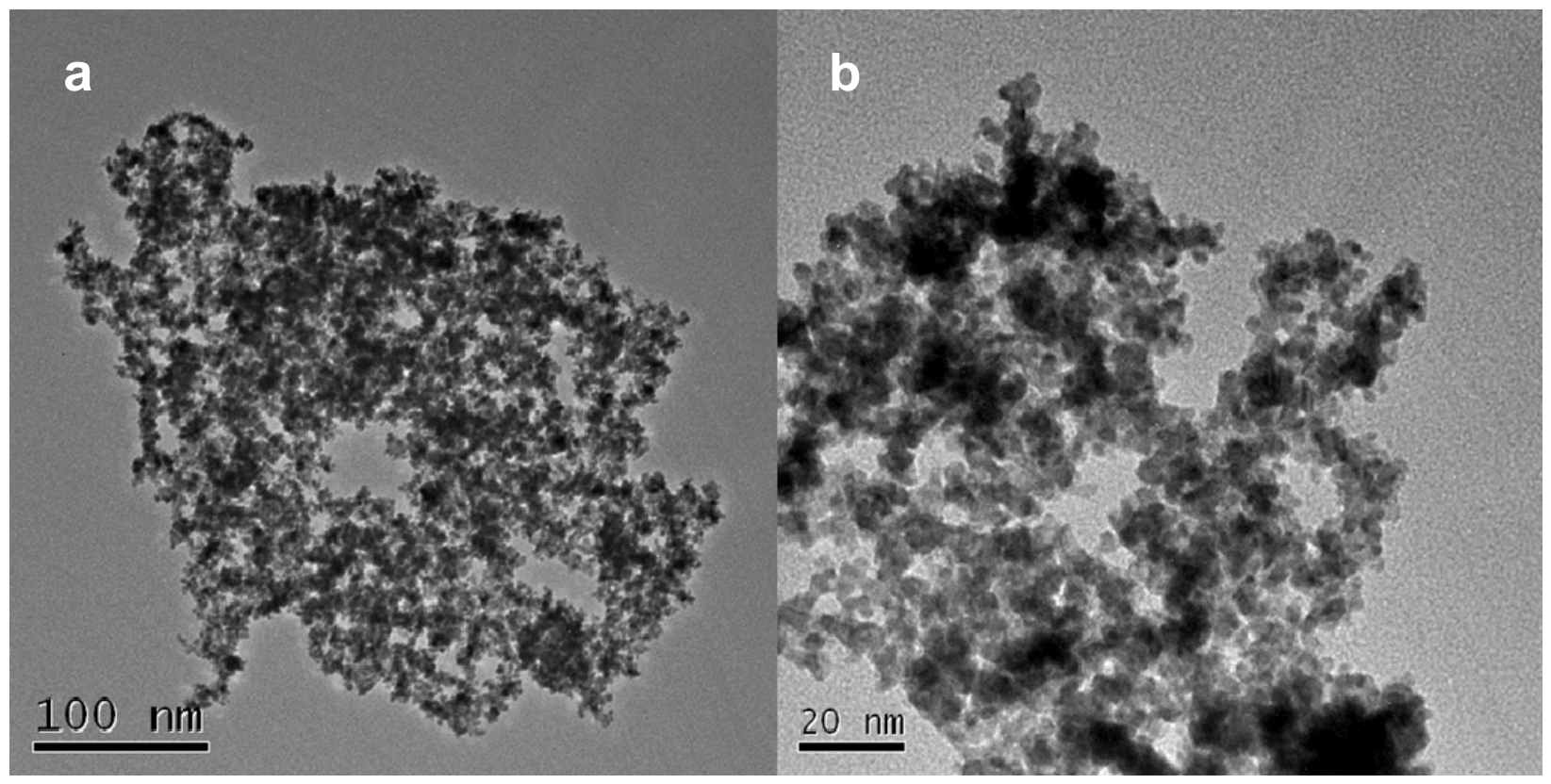

Figure S5. TEM images of aggregated platinum nanoparticles at (a) low and (b) high magnification. Reaction conditions: $10 \mathrm{~mL}$ of chloroform; 2-mM Pt(II) and 30-mM NaBH 4 in $100 \mathrm{~mL}$ of water; stirring at $1000 \mathrm{rpm}$. 